\title{
Evaluation of the Components of Psychological Capital and Organizational Citizenship Behavior among Nigerian Graduate Employees
}

\author{
John K. Aderibigbe*, Themba Q. Mjoli \\ Department of Industrial Psychology, University of Fort Hare, South Africa \\ 201607467@ufh.ac.za,tmjoli@ufh.ac.za
}

\begin{abstract}
In consideration of implications of organizational citizenship behavior, it is quite necessary for scholars and human resource management practitioners, to urgently investigate the correlates of psychological capital dimensions and the dimensions of organizational citizenship behavior. The purpose of the study was twofold. Firstly, to examines the relationship between psychological capital and organizational citizenship behavior. Secondly, to investigate the relationships between the dimensions of organizational citizenship behavior and psychological capital. The study is important, because its outcomes would help the corporate world, governments and human resource managers to avert the problem of underperformance among employees by improving psychological capital and organizational citizenship behavior. The study adopted the positivist explanatory cross-sectional (survey) research design to systematically sample opinions of 1,532 male and female graduate employees across the various sectors of the Nigerian economy, using a structured and validated questionnaire, and the Statistical Package for the Social Sciences (SPSS). The results of the statistical analysis of data showed that there was a significant positive relationship between psychological capital and organizational citizenship behavior, $r=0.588, p<0.01$. The results also showed that altruism, conscientiousness and civic virtue dimensions of organizational citizenship behavior are significantly positively interrelated to hope, optimism, resilience and self-efficacy dimensions of psychological capital. The study suggested that human resource managers should develop psychological capital in employees in order to increase the level of organizational performance. Recommendations of the study could assist in training and developing effective manpower capacity towards improving the economy of the nation.
\end{abstract}

Keywords: Graduate, employee, organizational citizenship behavior, psychological capital

\section{Introduction}

Organizational citizenship behavior and psychological capital are important constructs to the contemporary corporate world. Organizational citizenship behavior may be described as desirable dispositions of employees, which may contribute to the survival and success of organizations. Again, organizational citizenship behavior could be viewed as voluntary helping actions usually exhibited among employees to ensure the achievement of set corporate objectives. Psychological capital on the other hand, is viewed in this study as a strategic mission to elicit, maintain and promote corporate citizenship behavior among employees. The concept of psychological capital may be linked to the concept of motivation, which is relevant to employees' performance. The present harsh global economic situation might necessitate the need of employees to develop and nurture a winning spirit in the form of psychological capital - resilience, optimism, self-efficacy and hope, even in the face of the turbulent work environment and challenging situations at workplace. It is therefore, imperative for the competitive workforce to be indoctrinated in the psychology of positivity whose mission lays on psychological capital in achieving corporate performance.

Although, there is increasing consideration of the phenomenon of organizational citizenship behavior by researchers, a review of the literature shows a lack of agreement about the scope of the concept, (Farzianpour, Foroushani, Kamjoo \& Hosseini, 2011). However, the current study sought to empirically examine psychological capital as a correlate of organizational citizenship behavior in order to fill the existing vacuum identified in the literature. The purposes of the study are twofold. Firstly, to examines the relationship between psychological capital and organizational citizenship behavior. Secondly, to investigates the relationships between the dimensions of organizational citizenship behavior and psychological capital. Hence this study seeks to answer the following research questions: Could there be a significant positive relationship between psychological capital and organizational citizenship behavior? Are the dimensions of psychological capital significantly interrelated with the dimensions of organizational citizenship behavior? Parveen (2012) reports in his review of the literature on organizational citizenship behavior, a four- 
dimension model that consists of individual initiative, interpersonal helping, personal industry, and loyal boosterism behaviors.

\section{Conceptual Literature}

Organizational Citizenship Behavior: Organizational citizenship behavior, is an essential phenomenon in the formal work setting because of its potency to facilitate interpersonal relationships among employees, and also to increase organizational performance (Pradhan, Jena \& Bhattacharya, 2016). Organizational citizenship behavior is an alternative form of performance behavior, which is differentiated from the traditional performance that relies heavily on official assignments and tasks (Karolidis, 2016). For instance, having subordinates who are highly engaged in organizational citizenship may advance supervisors' efficacy by permitting them towards dedicating a better quantity of time to future strategic matters. Hence, supervisors, subordinates and the organizations at large benefit from positive behaviors (Lelei, Chepkwony \& Ambrose, 2016). These behaviors are explained by concepts such as pro-social behaviors, extra-role behaviors, contextual performance, spontaneous behaviors or organizational citizenship behavior. According to Behtooee (2016), there is no fixed agreement among scholars in the field of organizational citizenship behavior concerning the dimensions of the construct. The variations that were observed in the meaning and dimensions of organizational citizenship behavior may be as a result of differences in culture. It might be interpreted otherwise in different social contexts, given that what it means to be a "good citizen" may vary from nation to nation, particularly for those from the East and the West (Abd-Allah, 2016). For instance, a certain helping behavior that is exhibited by an individual may be recognized and appreciated in some contexts, and it may be understood in different ways, or it may be interpreted as motive-based, such as ingratiation, and probably cause unexpected troubles in interpersonal relationships at the workplace in some other cultures.

Furthermore, Ahmed and Khan (2016) report that the OCBI category includes altruism, maintenance of peace, and cheerfulness behaviors with intentions to assist others, while the OCBO category is composed of sportsmanship, civic virtue and conscientiousness; as well as organizational loyalty; endorsement and commitment to the organization's objectives; job devotion; taking charge; and upholding the company reputation. Additional concrete examples of OCBI, according to Ahmed and Khan (2016), are voluntarily assisting a newly employed staff member to access the organization's finance framework and praising a kindred staff on a new promotion. Similarly, presenting a novel knowledge to the organization on how the workforce process may be better, and being present at voluntary corporate meetings, are examples of OCBO (Ahmed \& Khan, 2016). Spik (2016), reports that organizational citizenship behavior consists of selfdevelopment, individual initiative sportsmanship, organizational compliance, organizational loyalty, civic virtue and helping. However, the most notable themes of organizational citizenship behavior are the five (civic virtue, conscientiousness, sportsmanship, altruism and courtesy) that were earlier identified by Organ, and which are commonly referred to by scholars in the field (Behtooee, 2016). Interpersonal helping behavior, according to Parveen (2012), involves assisting co-employees in their jobs when they need help. Individual initiative behavior implies communicating with other employees in the workplace in order to improve individual and group performances (Parveen, 2012). Personal industry relates to the performance of specific jobs far in excess of what was required, while loyal boosterism includes the promotion of the organizational image to outsiders (Parveen, 2012).

Though, in the meta-analysis of the literature on organizational citizenship behavior, which was conducted by Podsakoff, MacKenzie, Paine and Bachrach (2000), researchers identified about thirty different types of organizational citizenship behavior. Nevertheless, prior to the work of Podsakoff, MacKenzie, Paine and Bachrach (2000), a range of taxonomies was proposed to classify the behaviors that were identified as organizational citizenship. Podsakoff, MacKenzie, Paine and Bachrach (2000) advanced the taxonomy, and integrated the propositions of other scholars such as Organ, Podsakoff and MacKenzie. Helping behavior, according to Podsakoff, MacKenzie, Paine and Bachrach (2000), is a type of organizational citizenship behavior, which is similar to altruism. Such behavior involves voluntarily helping co-employees in solving work-related problems. It includes acts that improve morale, encourage, cooperation, and build and preserve good relationships in the workplace. Sportsmanship on the other hand involves bearing burdens and work 
difficulties without grumbling, being willing to relinquish individual enthusiasm for the benefit of the workgroup, while organizational loyalty encompasses promoting the company's image, remaining committed even under adverse conditions, defending an organization against external threats (Podsakoff, MacKenzie, Paine \& Bachrach, 2000). Organizational compliance, fourth on the list, is a type of organizational citizenship behavior that comprises all behaviors related to observing organizational rules and procedures, complying with organizational values, respect for authority, conscientiousness, meeting deadlines.

Individual initiative, on the other hand, is the act of trying to discover approaches to enhance person, group or organizational functioning including: voluntarily suggesting organizational improvements, demonstrations of imagination and development intended to improve one's tasks, while civic virtue implies responsible and useful contribution in the political procedure of the organization. It includes: presence at optional meetings, disseminating informed views with colleagues, being ready to deliver bad update if it is necessary for the good of the organization, and keeping abreast of different issues concerning the organization (Podsakoff, MacKenzie, Paine \& Bachrach, 2000). The last on the list of seven dimensions of organizational citizenship behavior as enlisted by Podsakoff, MacKenzie, Paine and Bachrach (2000) is self-development, which stands for self-training, and searching out and exploiting advanced instructional courses. It also involves being wellinformed of the up-to-date development in one's speciality, and learning new kinds of expertise in order to enlarge the array of one's input to an organization.

Williams and Anderson (1991) categorized organizational citizenship behavior into two classes based on the target beneficiary: organizational citizenship behaviors towards individuals such as the supervisor, subordinates and colleagues, and organizational citizenship behaviors toward the organization, such as those related behaviors that are performed for the betterment of the organization. Organizational citizenship behaviors towards the organization (OCBO) refer to the helping-behaviour which focuses on the organization as a whole. Examples include when a member of staff offers to render supplementary jobs as needed, or assists to establish useful meetings on themes, which are pertinent to all staff (Williams \& Anderson, 1991). On the other hand, organizational citizenship behavior (OCBI) implies helping-behaviour that is exhibited towards individual colleagues. An example of OCBI is employees who volunteer to help their co-employees who are absent from work or employees who are helping their subordinates to cope with work-related challenges (Williams \& Anderson, 1991).

Psychological Capital: Psychological capital is a compound concept that consists of hope, resilience, selfefficacy and optimism. Thus, collectively, hope, resilience, self-efficacy and optimism formed the concept of psychological capital. In other words, the four integral components of psychological capital are hope, resilience, self-efficacy and optimism (Luthans, Avolio, Avey, \& Norman, 2007). Specifically, Luthans, Avolio, Avey and Norman (2007) described self-efficacy as having the self-assurance to assume, and exert the required efforts to succeed in difficult professions. Moreover, Stajkovic and Luthans (1998) refer to selfefficacy as a person's belief about his/her mental ability, drive and forces that are essential to successfully implement a given assignment within a specific context. It is developed based on the theory of social cognition, which was propounded by Bandura (1997). Self-efficiency is not similar to the other three subconstructs (hope, optimism and resilience) of psychological capital. Bandura (1997) believes that self-efficacy could be improved through four specific approaches. First, it is believed that when a person is successful at overcoming a particular challenge, he or she will be more confident. Thus, the task mastery gives more selfassurance and aptitude to execute the next difficult tasks. Second, self-efficacy can be improved through a vicarious learning process, by observing significant others and imitating them. It implies that when an important person achieves success in a specific task, the observing person can upsurge his or her confidence in following such a model.

Third, the individuals who have earned another person's regard might be affected by his or her confidence in order to gain more buoyancy. For instance, if followers receive a positive comment from their leaders whom they hold in high esteem, they will have more assurance in accomplishing a given task. Fourth, personal confidence can be built by a caring attitude. For example, when a leader provides psychological support and cares for or appreciates his or her subordinates, in order to strengthen their existing relationship and improve performance. Hope, being one of the integral parts of the psychological capital, signifies the 
investment of the efforts of the persons that are working toward the attainment of set goals (Malone, 2010). However, Avey, Luthans, and Jenes's (2009) theory of hope incorporates three fundamental components: goals, paths and power. Pathways represent a person's aptitude to plan strategies of achieving desirable goals while agency denotes a person's perceived capability in applying such strategies as pathways to reach the anticipated goals. Moreover, the aim of agency is to inspire individuals to generate positive energy in achieving the given tasks while pathways are considered to be an avenue of reaching their objectives or to succeed at a given task (Avey, Luthans \& Jenes, 2009). Luthans, Norman, Avolio, and Avey (2008) describe hope as the determination of employees in moving towards achieving organizational objectives, besides the ability of individuals to advance paths in achieving goals when required.

According to Snyder, Sympson, Ybasco, Borders, Babyak and Higgins (1996), agency and pathways cannot function separately; both operate interdependently to accomplish a specific task. It therefore implies that an individual who is highly hopeful can generate multiple pathways to attain a specific target. Resilience, being the third component of psychological capital, is defined by Huong (2016), as a positively adaptable capability of an individual, which helps him or her to quickly recover from the effects of adversity, uncertainty or a failure situation. In other words, a resilient individual might be more compelling in an extensive variety of life exercises and negative occasions. Furthermore, it represents the development of good adaptation in the workplace, and plays an important role in healthy adaptations particularly to difficult life occasions (Durrah, Al-Tobasi, A'aqoulah, \& Ahmad, 2016). Kappagoda, Othman and De Alwis (2014) describe resilience as a positive force that is applicable in countering undesirable events, while Mills et al. (2013) defined resilience as the ability to bob over from disappointment and adversity. As a positive state, resiliency can be developed by imitating responses in not only adverse, but also on extremely positive occasions (Nguyen \& Nguyen, 2012). Besides, resilience can be enhanced by exhibiting and maintaining a positive emotion during the time of disappointment or negative events.

There are three main ideologies of resilience: coherence, connectedness and control (Enzi \& Ibrahim, 2012). It is also characterized by improvisation, objectivity, adaptation, deep faith and realism (Meng, Qi \& Li, 2011). Hence, highly resilient individuals who usually recover well and quickly after adverse occasions are completely dissimilar from those who perpetually stay bothered, and find it tough to push forward (Luthans, Avey, Avolio \& Peterson, 2010). Lastly, optimism, the fourth component of psychological capital is described as the propensity of an individual to keep up an uplifting viewpoint towards the future regardless of the present situation (Durrah, Al-Tobasi, A'aqoulah \& Ahmad, 2016). Literally, an optimist is an individual who anticipates good things while a pessimist is an opposite individual who imagines evil things to occur (Durrah, Al-Tobasi, A'aqoulah \& Ahmad, 2016). The development of optimism cuts across three areas. It can be developed intolerance toward the past. It can also be developed in valuation and estimating the present. Individuals can also develop optimism by focusing on the future (Durrah, Al-Tobasi, A'aqoulah \& Ahmad, 2016).

Again, the psychological state of optimism describes an explanatory style of the cause of behavior that mostly attributes positive events as originating from personality while the cause of negative events is usually attributed to external factors (Millard, 2011). According to Avey, Luthans and Pigeon (2010), an optimist believes that positive events occur, because of their own attitude and behaviors. In other words, the optimists are the individuals who dependably expect great things will come to them. Carver and Scheier (2002) also explained that highly rated optimists can advance efforts, even when facing an enduring difficult or challenging experience. Hence, to an optimist, he or she rarely nurture failures, and all undesirable results of action seem to be a challenge and a prospect to improve and aim at better results. Moreover, Schneider (2001) suggested that employees with a great level of optimism, particularly, realistic optimism, may increase their performance in work. Realistic optimism involves the process of improving and concentrating on the favorable aspects of individuals' experiences. It thus describes a scientific assessment of resource to complete a given task. 


\section{Empirical Literature Review}

The relationship between Psychological Capital and Organizational Citizenship Behavior: Shaheen, Bukhari and Adil (2016) surveyed the role of psychological capital on organizational citizenship behavior in a sample of 325 male and female bank employees of private and public sector banks in Islamabad and Rawalpindi cities of Pakistan. Their findings showed that psychological capital is a significant determinant of organizational citizenship behavior among the participants. Similarly, Pradhan, Jena and Bhattacharya (2016) investigated the relationship between psychological capital and organizational citizenship behavior among 212 professionals in the Indian manufacturing and service industries, and observed if emotional intelligence assumes a part in moderating the relationships between psychological capital and organizational citizenship behavior, using structural equation modelling. The outcomes of the structural equation modelling indicate that psychological capital is positively related to organizational citizenship behavior. Likewise, Suifan (2016) examined the impact of psychological capital on organizational citizenship behavior among 277 male and female staff of Jordanian banks, using a survey design and a questionnaire to elicit information from the participants. The results of the statistical analysis that was performed on the data based on the stated hypothesis showed that there is a significant positive relationship between psychological capital and organizational. Moreover, Paul, Bamel and Garg (2016) in their exploratory study of the relationship between resilience and organizational citizenship behavior within the context of Indian organizations, sampled 345 employees who were working in the manufacturing industries of Uttarakhand and Himachal Pradesh in India. Data were collected in the study with a self-administered questionnaire through the systematic sampling method. The findings of the study proved that there is a positive relationship between resilience and organizational citizenship behavior.

Relationship of Dimensions of Psychological Capital and Organizational Citizenship Behavior: Ali-Shah and Ali-Shah (2016) adopted a longitudinal research design approach to investigate the relationship between psychological capital and organizational citizenship behavior among 411 male and female employees of telecommunication firms in Pakistan, using a structured questionnaire as an instrument of data collection. The results of the investigation revealed that psychological capital and the in-role performance type of organizational citizenship behavior are significantly positively interrelated. Additionally, Rostiana and Lihardja (2013) conducted a survey to investigate the influence of psychological capital on organizational citizenship behavior among 205 participants in an office of a coal mining firm, using a validated questionnaire to measure the constructs that were involved in the study, and the data collected was processed statistically with ANOVA and regression techniques to test the hypothesis. The results of the study showed that psychological capital significantly influenced organizational citizenship behavior. Thus, it implies that psychological capital plays a crucial role in exhibiting in-role and extra-role performance.

Harris (2012) found in his doctoral degree research, which was conducted on the relationships between psychological capital, work engagement and organizational citizenship behavior in South African automotive dealerships, that there is a low positive correlation $(r=0.27)$ between organizational citizenship behavior and psychological capital. Harris (2012) further reported that both functional participation $(r=0.26)$ and sportsmanship $(r=0.22)$ dimensions of organizational citizenship behavior have a small positive relationship with psychological capital. In addition, according to Harris (2012), the results of the study further showed that self-efficacy $(r=0.24)$ and hope $(r=0.26)$ have low correlations with the total score of organizational citizenship behavior. As reported by Harris (2012), the hypothesized relationship between the dimensions of psychological capital and organizational citizenship behavior was also confirmed as the results showed that there is a low correlation between functional participation and self-efficacy $(r=0.24)$ and hope $(r=0.25)$, while sportsmanship has a low correlation with optimism $(r=0.30)$.

Statement of Hypotheses: Based on the past studies reviewed and on logical grounds, the present study states the following hypotheses:

\section{Hypothesis 1}

$\mathbf{H}_{0}$ : Psychological capital is not significantly positively correlated with organizational citizenship behavior. 
$\mathbf{H}_{1}$ : Psychological capital is significantly positively correlated with organizational citizenship behavior.

\section{Hypothesis 2}

Ho: Self-efficacy, hope, optimism and resilience are not significantly positively interrelated to civic virtue, conscientiousness and altruism.

H1: Self-efficacy, hope, optimism and resilience are significantly positively interrelated to civic virtue, conscientiousness and altruism

\section{Methodology}

Research Design, Sample and Procedure: The study adopted a positivist explanatory cross-sectional (survey) research design. The positivist explanatory cross-sectional (survey) research was considered appropriate for the study, because the research used the positivist approach by means of quantitative data generation, and hypotheses testing (Bhattacherjee, 2012). The chosen research design was also considered appropriate in the study, because of the study cut-across the private and public sectors of the national economy thus, incorporated diverse industries.

The stratify type of probability (Two-stage North Carolina Centre for Public Health Preparedness', 2013 sampling scheme) technique was adopted along with The Research Advisor's (2006) Sample Size Calculation Table, and used in calculating the appropriate sample size of the study. According to the Federal Ministry of Women Affairs and Social Development (2008), there were a total number of 40,567,978 male and female employees across industries in Nigeria as at the year 2007. In applying the stratified sampling method as recommended by the North Carolina Centre for Public Health Preparedness, 10\% of 40,567,978 was calculated at the first stage, which reduced the number to 4,056,797. Again, at the second stage, $10 \%$ of $4,056,797$ were calculated. Consequently, the result further reduced the number to 405,679. Nevertheless, at this point, the researchers subjected the derived figure of 405,679 to the recommendation of the Research Advisor (2006), which approves a sample size of 1,532 (at 95\% level of confidence and 2.5\% margin of error) out of an approximate population of 500,000 for a national survey. Hence, the researchers were $95 \%$ confident of the population sampled being a true representation of the study's targeted population. Thus, a total of 1,532 male and female graduate employees formed the sample size of the study.

In addition, the convenience and purposive types of non-probability sampling technique were employed in selecting participants for the study. Firstly, the convenience sampling technique was applied in selecting the three most suitable states (Oyo, Osun and Lagos States) out of the thirty-six states in Nigeria, as the sites of the field work. The rationale for selecting the three states is that each of them houses one or the other of the renowned public and private universities (University of Ibadan, Obafemi Awolowo University, and the PanAtlantic University) where the study sample was offered part-time postgraduate admissions of MBA programmes as working-class postgraduate students with a minimum of three-year employment experience. Another reason for adopting the convenience sampling technique was because the fieldwork became easier when the participants were met in groups at conducive places such as in the lecture-rooms and relaxation centres within the university premises. Furthermore, since the study was designed only for the graduate employees, the purposive sampling technique was also introduced and applied, to ensure that participants in the study were employed during the period of the field work, and that they were graduates of universities and polytechnics. The sample comprised of 916 (60\%) male and $616(40 \%)$ female graduate employees from 19 sectors of the Nigerian economy.

Among the participants, $202(13.2 \%)$ were graduate employees from the educational sector, 38 (2.5\%) from the research institutes, $51(3.3 \%)$ from the transportation sector, $291(19 \%)$ from the finance and insurance sector, 83 (5.4\%) from the fast-moving and consumable goods (FMCG) Industry, 21 (1.4\%) from the commercial sector, $70(4.6 \%)$ from the healthcare sector, $8(0.5 \%)$ from the aviation sector, $77(5.0 \%)$ from the agricultural sector, 57 (3.7\%) from the information. All participants were Nigerians English speakers. The participants' ages ranged from 20 years to 65 years old. Relatively, $974(63.6 \%)$ of the participants were senior staff while the remaining 558 (36.4\%) were junior staff. Conclusively, among the participants, 730 
(47.7\%) were employed by the government while the remaining $802(52.3 \%)$ were working under the employment of private organizations. Data were collected by means of paper-pencil inventories (structured validated questionnaires), which were distributed to employees in the large lecture auditoriums during their weekend (Saturdays) part-time professional postgraduate programs, in the three renowned public and private universities (University of Ibadan, Obafemi Awolowo University and the Pan-Atlantic University), situated in Oyo, Osun and Lagos states of Nigeria.

Ethical Consideration: The participants' voluntary participation in the study was sought through a letter of consent, signed by each of the participants. The participants were informed about the importance of the study as the findings from the study may positively influence the government policy helping in improving their conditions of employment and service respectively. Moreover, assurance was given to the participants in respect of confidentiality of all information supplied. Furthermore, the participants were instructed not to indicate any means of identification such as name, identity number or organizational affiliation. With the utmost sense of sincerity, information concerning the study and its outcomes was accurately submitted to the appropriate institutions. Thus, it was ensured that no instance of misleading actions was demonstrated in the course of the study. The researchers also ensured that the study was conducted in a conducive environment such that would not expose the participants to any physical or psychological hazard. The Research Ethics Committee of the University of Fort Hare furthermore granted approval for ethical clearance of the study (Certificate reference number: MJO071SADE01). Likewise, the results indicate that there is a significant positive relationship between organisational citizenship behaviour and conscientiousness, $r=0.755, p<0.01$.

Measuring Instrument: Two established scales of measurement were employed to assess psychological capital, and organizational citizenship behavior.

Psychological Capital: A 24-item scale of psychological capital that was developed and validated by Luthans, Avolio, Avey and Norman (2007) was utilised to measure psychological capital. The construct consisted of self-efficacy, hope-state, optimism-state and resilience-state sub-scales, with a 5-point Likert-type response format ranging from $1 /$ (Strongly disagree) to $5 /$ (Strongly agree). The authors reported a Cronbach Alpha coefficient score of 0.91 for the scale. However, the outcome of the pilot factor analysis of this study reduced the scale-item to 21, and yielded Cronbach Alpha coefficient scores of 0.88 (self-efficacy), 0.91 (hope), 0.85 (resilience), 0.67 (optimism) and 0.94 for the whole scale of psychological capital, while the main study's factor analysis yielded a Cronbach Alpha coefficient score of 0.85 for the whole scale of psychological capital.

Organizational Citizenship Behavior: A 15-item modified version of Podsakoff, Mackenzie, Moorman, and Fetter's (1990) organizational citizenship behavior questionnaire by Argentero, Cortese and Ferretti (2008) was utilised to measure organizational citizenship behavior. The construct consisted of altruism, conscientiousness and civic virtue sub-scales, with a 5-point Likert-type response format ranging from 1/(Strongly disagree) to 5/(Strongly agree). Argentero, Cortese and Ferretti (2008) reported the following Cronbach Alpha coefficients for the scale: altruism $=0.81$, conscientiousness $=0.73$, civic virtue $=0.73$ and 0.84 for the whole scale of organizational citizenship behavior. However, the outcome of the pilot factor analysis of this study reduced the scale-item to 13, and yielded Cronbach Alpha coefficient of 0.88 (altruism), 0.81 (conscientiousness), 0.86 (civic virtue) and 0.93 for the whole scale of organizational citizenship behavior, while the main study's factor analysis yielded a Cronbach Alpha coefficient score of 0.82 for the whole scale of organizational citizenship behavior.

Statistical Analysis of Data: The data generated from 1,532 screened questionnaires were analyzed based on the hypotheses stated, using version 20 of the Statistical Package for the Social Sciences (SPSS). All hypotheses stated were analyzed, using Pearson Correlation Analysis.

\section{Research Results}

The results of the analysis are presented in table 1 below: 
Table 1: A Summary Table of Pearson Correlation Analysis Showing the Relationships among OCB, PSYCAP, the Four Dimensions of OCB, and the Four Dimensions of PSYCAP

\begin{tabular}{lccccccccc}
\hline Variable & $\mathbf{1}$ & $\mathbf{2}$ & $\mathbf{3}$ & $\mathbf{4}$ & $\mathbf{5}$ & $\mathbf{6}$ & $\mathbf{7}$ & $\mathbf{8}$ & $\mathbf{9}$ \\
\hline 1) OCB & 1 & $.885^{* *}$ & $.755^{* *}$ & $.843^{* *}$ & $.516^{* *}$ & $.495^{* *}$ & $.444^{* *}$ & $.373^{* *}$ & $.473^{* *}$ \\
2) Altruism OCB & $.885^{* *}$ & 1 & $.522^{* *}$ & $.523^{* *}$ & $.440^{* *}$ & $.432^{* *}$ & $.402^{* *}$ & $.296^{* *}$ & $.440^{* *}$ \\
3) Conscien OCB & $.755^{* *}$ & $.522^{* *}$ & 1 & $.495^{* *}$ & $.428^{* *}$ & $.395^{* *}$ & $.342^{* *}$ & $.306^{* *}$ & $.362^{* *}$ \\
4) Civic virt. OCB & $.843^{* *}$ & $.523^{* *}$ & $.495^{* *}$ & 1 & $.413^{* *}$ & $.396^{* *}$ & $.347^{* *}$ & $.323^{* *}$ & $.359^{* *}$ \\
5) Self-Eff. PSYCAP & $.516^{* *}$ & $.440^{* *}$ & $.428^{* *}$ & $.413^{* *}$ & 1 & $.622^{* *}$ & $.501^{* *}$ & $.403^{* *}$ & $.438^{* *}$ \\
6) Hope PSYCAP & $.495^{* *}$ & $.432^{* *}$ & $.395^{* *}$ & $.396^{* *}$ & $.622^{* *}$ & 1 & $.497^{* *}$ & $.448^{* *}$ & $.404^{* *}$ \\
7) Resilience PSYCAP & $.444^{* *}$ & $.402^{* *}$ & $.342^{* *}$ & $.347^{* *}$ & $.501^{* *}$ & $.497^{* *}$ & 1 & $.381^{* *}$ & $.369^{* *}$ \\
8) Optimism PSYCAP & $.373^{* *}$ & $.296^{* *}$ & $.306^{* *}$ & $.323^{* *}$ & $.403^{* *}$ & $.448^{* *}$ & $.381^{* *}$ & 1 & $.345^{* *}$ \\
9) PSYCAP & $.588^{* *}$ & $.440^{* *}$ & $.362^{* *}$ & $.359^{* *}$ & $.438^{* *}$ & $.404^{* *}$ & $.369^{* *}$ & $.345^{* *}$ & 1 \\
\hline
\end{tabular}

**. Correlation is significant at the 0.01 level (2-tailed).

The results of correlation analysis in table 1 above show that there is a significant positive relationship between organisational citizenship behaviour and psychological capital $r=0.440, p<0.01$. This implies that organisational citizenship behaviour is significantly positively related to psychological capital. The results in table1 also indicate that there is a significant positive relationship between organisational citizenship behaviour and altruism, $r=0.885, \mathrm{p}<0.01$. It confirms that altruism is, indeed, strongly related to organizational citizenship behavior. The results further show that there is a significant positive relationship between organisational citizenship behaviour and civic virtue, $r=0.843, p<0.01$. It also confirms that civic virtue is strongly related to organization citizenship behavior. It also confirms that conscientiousness is strongly related to organizational citizenship behavior.

Moreover, from the results in Table 1, there is a significant positive relationship between organizational citizenship behavior and the self-efficacy component of psychological capital, $r=0.516, p<0.01$. The result implies that as self-efficacy increases so also do organizational citizenship behavior. Similarly, the results in the table above show that there is a significant positive relationship between organizational citizenship behavior and the hope component of psychological capital, $r=0.495, p<0.01$. It also means that as the level of hope increases so the level of organizational citizenship behavior increases. Furthermore, the results in Table 1 show that there is a significant positive relationship between organizational citizenship behavior and the resilience component of psychological capital, $r=0.444, p<0.01$. It implies that organizational citizenship behavior and resilience move together in the same direction. Additionally, from the same table, results indicate that there is a significant positive relationship between organizational citizenship behavior and the optimism component of psychological capital, $r=0.373, p<0.01$. The result suggests that organizational citizenship behavior positively and directly correlated with resilience. In addition, from Table 1, the results reveal that there is a significant positive relationship between altruism and conscientiousness, $r=0.522$, $\mathrm{p}<0.01$.

The results also indicate that there is a significant positive relationship between altruism and civic virtue, $\mathrm{r}=$ $0.523, \mathrm{p}<0.01$. Similarly, the results show that there is a significant positive relationship between altruism and self-efficacy, $r=0.440, p<0.01$. Equally, the results suggest that there is a significant positive relationship between altruism and hope, $r=0.432, p<0.01$. Likewise, the results depict that there is a significant positive relationship between altruism and resilience, $r=0.402, p<0.01$. Furthermore, the results illustrate that there is a significant positive relationship between altruism and optimism, $r=0.296, p<0.01$. Similarly, the results in Table 1 reveal that there is a significant positive relationship between conscientiousness and civic virtue, $r$ $=0.495, \mathrm{p}<0.01$. In the same way, the results reveal that there is a significant positive relationship between conscientiousness and self-efficacy, $r=0.428, p<0.01$. Correspondingly, the results show that there is a significant positive relationship between conscientiousness and hope, $r=0.395, p<0.01$. Also, it shows that there is a significant positive relationship between conscientiousness and resilience, $r=0.342, p<0.01$. Moreover, the results show that there is a significant positive relationship between conscientiousness and optimism, $r=0.306, p<0.01$. Furthermore, from Table 1 , the results indicate that there is a significant positive relationship between civic virtue and self-efficacy, $r=0.413, p<0.01$. Likewise, the results demonstrate that there is a significant positive relationship between civic virtue and hope, $r=0.396, p<0.01$. 
In the same vein, the results demonstrate that there is a significant positive relationship between civic virtue and resilience, $r=0.347, p<0.01$. Equally, the results indicate that there is a significant positive relationship between civic virtue and optimism, $r=0.323, p<0.01$. In the same way, the results in Table 1 show that there is a significant positive relationship between self-efficacy and hope, $r=0.622, p<0.01$. Likewise, the results establish that there is a significant positive relationship between self-efficacy and resilience, $r=0.501$, $\mathrm{p}<0.01$. At the same time, the results demonstrate that there is a significant positive relationship between self-efficacy and optimism, $r=0.403, p<0.01$. Moreover, from the results in Table 1 , it is found that there is a significant positive relationship between hope and resilience, $r=0.497, \mathrm{p}<0.01$. Similarly, there is also a significant positive relationship between hope and optimism, $r=0.448, p<0.01$. Additionally, from the same table, results indicate that there is a significant positive relationship between resilience and optimism, $\mathrm{r}=$ $0.381, p<0.01$. The summary of the above interpretations is that the intercorrelation matrix of the dimensions of organizational citizenship behavior and psychological capital, which are shown in Table 1 demonstrates that all the dimensions are positively interrelated with one another, including the two main variables (organizational citizenship behavior and psychological capital). Conclusively, the descriptive analyses showing means and standard deviations of participants' responses on the two main variables and their dimensions are presented in Table 2 below.

Limitations and Suggestions: The first noticeable shortcoming of this research relates to bias in the approach of data collection. The research only adopted the quantitative method, which limited the opinions of research respondents to the response options provided to statements in the questionnaire. This study therefore, suggests that future studies should consider adopting more than one method of data collection. The second acknowledged limitation of this study is the fact that the study was designed only to explore the relationships among variables under consideration. Because of this reason, the study could not specifically categorize variables into classes of dependence and independence, therefore further limits the generalization of the findings.

Table 2: A Summary Table of Descriptive Analysis Showing the Mean Difference and Standard Deviation among OCB, the three Dimensions of OCB, the four Dimensions of PSYCAP, Emotional Awareness of others (Emotional Intelligence) and Occupational Stress

\begin{tabular}{llll}
\hline Variable & $\mathbf{N}$ & $\boldsymbol{X}$ & SD \\
\hline Psychological capital & 1532 & 60.4817 & 8.49292 \\
& & & \\
Organizational citizenship behavior & 1532 & 52.3890 & 6.94911 \\
Self-efficacy (psycap) & 1532 & 20.3845 & 3.54578 \\
Hope (psycap) & 1532 & 20.5281 & 3.40532 \\
Resilience (psycap) & 1532 & 15.3544 & 2.59459 \\
Optimism (psycap) & 1532 & 8.0424 & 1.65358 \\
& & & \\
Altruism (OCB) & 1532 & 20.0020 & 3.25440 \\
Conscientiousness (OCB) & 1532 & 11.8035 & 1.97103 \\
Civic virtue (OCB) & 1532 & 20.5836 & 3.17756 \\
Valid N (listwise) & 1532 & & \\
\hline
\end{tabular}

The results in Tables 2 above show the levels at which the participants possessed each of the variables of consideration in the study. For instance, the results of descriptive statistics show that the participants demonstrated a higher level of psychological capital, $\bar{X}=60.482, \mathrm{SD}=8.493$. The results imply that the participants in the study are positively oriented about themselves. Similarly, the results in the Table 2 above show that participants expressed a high level of organizational citizenship behavior, $\bar{X}=52.389, \mathrm{SD}=6.949$, which also indicates that the participants are highly interested in helping their colleagues at work, at the same time ensuring that their personal and organizational goals are achieved. The results further reveal that participants expressed significantly higher levels of civic virtue, $\bar{X}=20.584, \mathrm{SD}=3.178$; hope, $\bar{X}=20.528$, 
$\mathrm{SD}=3.405$; self-efficacy, $\bar{X}=20.385, \mathrm{SD}=3.546$; altruism, $\bar{X}=20.002, \mathrm{SD}=3.254$; resilience, $\bar{X}=15.354$, $\mathrm{SD}=2.595$; conscientiousness, $\bar{X}=11.804, \mathrm{SD}=1.971$; and optimism, $\bar{X}=8.042, \mathrm{SD}=1.653$.

Discussion: The results established the hypothesized relationship between psychological capital and organizational citizenship behavior. It also confirmed the hypothesized interrelationships among the components of psychological capital and organizational citizenship behavior. The results of hypothesis 1 show that there is a significant positive relationship between organizational citizenship behavior and psychological capital. The result implies that organizational citizenship behavior is significantly positively related to psychological. The result is in line with the expectation that employees with higher levels of positive orientations will contribute significantly higher, beyond the border or scope of their job duties and responsibilities, to assist co-employees and customers or client in order to enable the organization to achieve her goals and objectives. The present findings corroborate the findings of Ali-Shah and Ali-Shah (2016), which revealed that psychological capital and the in-role performance type of organizational citizenship behavior are significantly positively interrelated. Similarly, Suifan (2016), reports that there is a significant positive relationship between psychological capital and organizational citizenship behavior.

Moreover, Paul, Bamel and Garg's (2016) study demonstrated that there is a positive relationship between resilience and organizational citizenship behavior. The results of hypothesis 2 show that there are significant positive interrelationships among the components of organizational citizenship behavior and psychological capital. The results imply that psychological capital dimensions and organizational citizenship behavior components are all positive human behavioral dispositions that move concurrently along each other in the same direction. In other words, in relation to the Nigerian graduate employees' experience, the graduate employees who perpetually exhibit citizenship behavior at work, even in the face of the peculiar tough work environment of Nigeria, are those who have discovered, developed and are constantly demonstrating reasonable levels of hope, optimism, resilience and self-efficacy when saddled with difficulties on official responsibilities. This is to say that extra-role performance is rooted in the human psychological states of hope, optimism, resilience and self-efficacy.

For instance, a highly hopeful graduate employee is constantly motivated by his or her positive perception of the job or career, and willing to give his or her best on the official assignments with the belief that he or she is building a brighter career future, even while helping the colleagues and the organization at large to meet the set goals and objectives. Such a graduate employee will drive the work team with his vision, to perform beyond the criterion. Likewise, the states of self-efficacy, optimism and resilience drive a graduate employee who is found to possess the aforementioned psychological states at higher levels, and propel him or her to engage in citizenship behavior in the workplace. In support of the above, Ali-Shah and Ali-Shah (2016) report that psychological capital and the in-role performance type of organizational citizenship behavior are significantly positively interrelated. Additionally, the results of the study that was conducted by Rostiana and Lihardja (2013) showed that psychological capital significantly influenced organizational citizenship behavior. Thus, it implies that psychological capital plays a crucial role in exhibiting in-role and extra-role performance.

Harris (2012) found in his doctoral degree research, which was conducted on the relationships between psychological capital, work engagement and organizational citizenship behavior in South African automotive dealerships, that there is a low positive correlation $(r=0.27)$ between organizational citizenship behavior and psychological capital. Harris (2012) further reported that both functional participation $(r=0.26)$ and sportsmanship ( $\mathrm{r}=0.22)$ dimensions of organizational citizenship behavior have a small positive relationship with psychological capital. In addition, according to Harris (2012), the results of the study further showed that self-efficacy $(r=0.24)$ and hope $(r=0.26)$ have low correlations with the total score of organizational citizenship behavior. As reported by Harris (2012), the hypothesized relationship between the dimensions of psychological capital and organizational citizenship behavior was also confirmed as the results showed that there is a low correlation between functional participation and self-efficacy $(r=0.24)$ and hope $(r=0.25)$, while sportsmanship has a low correlation with optimism $(r=0.30)$. 


\section{Conclusion}

\section{The Study Makes the Following Conclusions:}

- There is a significant positive relationship between psychological and organizational citizenship behavior.

- Altruism, civic virtue and conscientiousness are all significantly positively interrelated to selfefficacy, resilience, optimism and hope.

Recommendations: In view of the above discussion and conclusions, the researchers make the following practical recommendations: The tertiary institutions' management, most especially of the university authorities, should incorporate in their academic curricula some practical simulated work exercise that will pre-expose the graduating students to the challenges at the world of work. This will build their psyche, and make them mentally ready for the challenges in the corporate world, even in the cause of discharging of career duties or responsibilities through the positivist approach. This can be achieved by a deliberate inclusion of moderately difficult practical group assignments in the syllabus that will task each student in a group, to proactively think 'outside the box' and proffer visible solutions in the form of suggestions to the problems at hand. By so doing, students will develop a reasonable level of positive orientations along with the acquired theoretical knowledge of their disciplines while the universities can as well boast of producing a capable graduate who will fit perfectly into the realities of the world of work and promptly deliver. Human resource managers, seminar facilitators, workshop trainers and supervisors should focus on training the individual employees or graduates to discover their covert psychological states of development such as psychological capital and make them refined through a systematic training process that converts the covert behavioural gifts into overt psychological assets in the form of demonstrable managerial competencies, which can enhance their performance on the job, and enable them to be pro-social among colleagues in the work settings.

\section{Acknowledgements}

Competing Interests: The authors declare that they have no financial or personal relationships that may have inappropriately influenced them in writing this article.

Authors' Contributions: The first author was the $\mathrm{PhD}$ researcher who designed, developed and implemented the research blueprint under the research supervising of the second author.

\section{References}

Abd-Allah, 0. M. Z. (2016). The relationship between organizational citizenship behavior and employee engagement in cement industry in Egypt. International Journal of Management and Commerce Innovations, 4(1), 362-376.

Ahmed, S. W. \& Khan, T. (2016). Does motivation lead to organizational citizenship behavior? - A Theoretical Review. Global Journal of Management and Business Research: A Administration and Management, 16(7), 43-49.

Ali-Shah, T. \& Ali-Shah, S. Z. (2016). Combined effects of psychological capital and psychological contract on employees' job level outcomes. European Journal of Business and Management, 8(26), 5-19.

Argentero, P., Cortese, C. G. \& Ferretti, M. S. (2008). Organizational citizenship behavior: Podsakoff et al.'s scale. TPM, 15(2), 61-75.

Avey, J., Luthans, F. \& Jenes, S. (2009). Psychological capital: A positive resource for combating employee stress and turnover. Human Resource Management, 48(5), 677-693.

Bandura, A. (1997). Self-efficacy: The exercise of control. New York, NY: Freeman.

Behtooee, L. (2016). A model for explanation of social capital in organizations, psychological empowerment, job involvement, and organizational citizenship behavior. International Journal of Advanced and Applied Sciences, 3(5), 80-87.

Bhattacherjee, A. (2012). Social science research: Principle, methods and practices. Textbook collection. Book 3. 
Carver, C. S. \& Scheier, M. F. (2002). Optimism, pessimism, and self-regulation. In E.C. Chang (Ed.), Optimism and pessimism: Implication for theory, research and practice. United States of America: American Psychological Association.

Durrah, O., Al-Tobasi, A., A'aqoulah, A. \& Ahmad, M. (2016). The impact of the psychological capital on job performance: A case study on faculty members at Philadelphia University. International Review of Management and Marketing, 6(2), 183-191.

Enzi, S. \& Ibrahim, I. (2012). Positive psychological capital (conceptual perspective in core basics and requirements for building and preparing). Journal of Economic and Administrative Sciences, 18(65), 131.

Farzianpour, F., Foroushani, A. R., Kamjoo, H. \& Hosseini, S. S. (2011). Organizational citizenship behavior (OCB) among the managers of teaching hospitals. American Journal of Economics and Business Administration, 3(3), 534-542.

Harris, C. (2012). Relationships between psychological capital, work engagement and organizational citizenship behavior in South African automotive dealerships. Doctoral Degree Thesis, Department of Industrial Psychology, Nelson Mandela Metropolitan University, South Africa.

Huong, T. H. T. (2016). Psychological capital and quality of work life among employees in public sector: Evidence from Ho Chi Minh City Department of Culture and Sports. Master Thesis, University of Tampere.

Kappagoda, S., Othman, H. \& De Alwis, G. (2014). The impact of psychological capital on job performance: Development of a conceptual framework. European Journal of Business and Management, 6(14), 143154.

Karolidis, D. (2016). Organizational citizenship behavior in the Greek public sector. Interdependent Program me of Postgraduate Studies in Business Administration, University of Macedonia.

Lelei, J. C., Chepkwony, P. K. \& Ambrose, K. (2016). Effect of organizational citizenship behavior on employee performance in banking sector, Nairobi County, Kenya. International Journal of Business, Humanities and Technology, 5(4), 55-61.

Luthans, F., Avey, J. B., Avolio, B. J. \& Peterson, S. J. (2010). The development and resulting performance impact of positive psychological capital. Human Resource Development Quarterly, 21, 41-67.

Luthans, F., Avolio, B. J., Avey, J. B. \& Norman, S. M. (2007). Psychological capital: Measurement and relationship with performance and satisfaction. Personnel Psychology, 60, 541-572.

Luthans, F., Norman, S., Avolio, B. \& Avey, J. (2008). The mediating role of psychological capital in the supportive organizational climate employee performance relationship. Journal of Organizational Behavior, 29, 219-238.

Luthans, F. \& Youssef, C. (2004). Human, social, and now positive psychological capital management. Organizational Dynamics, 33(2), 152-155.

Malone, L. (2010). Individual differences and stress reactions as predictors of performance in pilot trainees. Master Thesis, Manhattan, Kansas: Kansas State University.

Meng, Y., Qi, S. \& Li, L. (2011). A study on the impact of hotel leaders' psychological capital on employee engagement, service systems and service management (ICSSSM). 8th International Conference On, 25-27 June, Tianjin.

Millard, M. (2011). Psychological net worth: Finding the balance between psychological Capital and psychological debt, Doctoral Thesis, University of Nebraska - Lincoln.

Mills, J. M., Fleck, C. R. \& Kozikowski, A. (2013). Positive psychology at work: A conceptual review, state-ofpractice assessment, and a look ahead. The Journal of Positive Psychology, 8(2), 153-164.

Nguyen, T. D. \& Nguyen, T. T. (2012). Psychological capital, quality of work life, and quality of life of marketers' evidence from Vietnam. Journal of Macro marketing, 32(1), 87-95.

North Carolina Center for Public Health Preparedness. (2013). Two-stage cluster sampling: general guidance for use in public health assessments. Cited in Aramide, O.K. (2014). Relationship between the use of family planning related information and attitudes of rural childbearing women toward family planning. A Ph. D Thesis, Postgraduate School, Babcock University, Nigeria, 73-75.

Parveen, D. (2012). Organizational Citizenship Behavior and Job Tenure: An Empirical Study at Indian Organizations. Indian Journal of Psychological Science, 6(1), 124-132.

Paul, H., Bamel, U. K. \& Garg, P. (2016). Employee resilience and organizational citizenship behavior: Mediating effects of organizational commitment. The Journal for Decision Makers, 41(4), 308-324. 
Podsakoff, P. M., Mackenzie, S. B, Moorman, R. H. \& Fetter, R. (1990). Transformational leader behaviors and their effects on followers' trust in leader, satisfaction and organizational citizenship behavior. The Leadership Quarterly, 1(2), 107-142.

Podsakoff, P. M., MacKenzie, S. B., Paine, J. B. \& Bachrach, D. G. (2000). Organizational Citizenship Behaviors: A Critical Review of the Theoretical and Empirical Literature and Suggestions for Future Research. Journal of Management, 26(3), 513-563.

Pradhan, R. K. \& Jena, L. K. \& Bhattacharya, P. (2016). Impact of psychological capital on organizational citizenship behavior: Moderating role of emotional intelligence. Cogent Business \& Management, 3(1), 1-16.

Rostiana, D. \& Lihardja, N. (2013). The influence of psychological capital to work engagement and organizational citizenship behavior. International conference on entrepreneurship and business management, Sanur, Bali - November 21-22, ISBN: 978-979-9234-49-0.

Schneider, S. (2001). In search of realistic optimism meaning, knowledge, and warm fuzziness. American Psychologist, 56(3), 250-263.

Shaheen, S., Bukhari, I. \& Adil, A. (2016). Moderating role of psychological capital between perceived organizational support and organizational citizenship behavior and its dimensions. International Journal of Research Studies in Psychology, 5(2), 41-50.

Snyder C. R, Sympson, S., Ybasco, F., Borders, T., Babyak, M. \& Higgins, R. (1996). Development and validation of the state hope scale. Journal of Personality and Social Psychology, 70, 321-335.

Spik, A. (2016). Enthusiasts or trapped? - Relations between organizational commitment profiles, organizational citizenship behavior and life satisfaction. Journal of Entrepreneurship, Management and Innovation (JEMI), 12(1), 7-34.

Stajkovic, A. D. \& Luthans, F. (1998). Self-efficacy and work-related performance: A meta-analysis. Psychological Bulletin, 124, 240-261.

Suifan, T. S. (2016). The impact of organizational climate and psychological capital on organizational citizenship behavior. International Journal of Business and Management, 11(1), 224-230.

The Research Advisors. (2006). http://research-advisors.com

Williams, L. J. \& Anderson, S. E. (1991). Job satisfaction, and organizational commitment as predictors of organizational citizenship and in-role behaviors. Journal of Management, 17, 601-617. 